\title{
Basaloid Squamous Cell Carcinoma of the Penis
}

National Cancer Institute

\section{Source}

National Cancer Institute. Basaloid Squamous Cell Carcinoma of the Penis. NCI

Thesaurus. Code C6980.

An aggressive, human papillomavirus-related squamous cell carcinoma that arises from the penis. It is characterized by the presence of nests of small malignant cells. The malignant cells tend to invade deeply into the adjacent tissues. Comedo-type necrosis is often present. 